\title{
The role of geography and host abundance in the distribution of parasitoids of an alien pest
}

Petra Novakova, Jaroslav Holusa, Jakub Horak

Chalcid wasps (Hymenoptera: Chalcidoidea) are probably the most effective and abundant parasitoids of the horse chestnut leaf miner (Cameraria ohridella), an alien pest in Europe that lacks specialized enemies. We studied how the species richness and abundance of chalcids are influenced by altitude, direction of an alien spread and host abundance of $C$. ohridella. We quantified the numbers and species richness of chalcid wasps and the numbers of $C$. ohridella that emerged from horse chestnut (Aesculus hippocastanum) leaf litter samples collected from 35 sites in the Czech Republic. Species richness of chalcids, which was considered an indicator of the possible adaptation of parasitoids to this alien host, was unrelated to $C$. ohridella abundance, direction of spread, or altitude. Chalcid abundance, which was considered an indicator of parasitism of the alien host, was strongly and positively related to $C$. ohridella abundance. Chalcid abundance was negatively related to direction of spread and positively related, although in a non-linear manner, to altitude. The relationship of chalcid abundance with direction of spread and altitude was weaker than that with $C$. ohridella abundance. The results provide evidence that biological control of the alien pest $C$. ohridella by natural enemies might develop in the future. 
1 The role of geography and host abundance in the distribution of parasitoids of an alien pest

2

3 Running title: Natural enemies and alien pest

4

5 Petra Nováková, Jaroslav Holuša and Jakub Horák*

6

7 Faculty of Forestry and Wood Sciences, Czech University of Life Sciences Prague, Kamycka

8 1176, CZ-165 21 Prague, Czech Republic

9

*Corresponding author, e-mail: jakub.sruby@gmail.com

\section{ABSTRACT}

13 Chalcid wasps (Hymenoptera: Chalcidoidea) are probably the most effective and abundant

14 parasitoids of the horse chestnut leaf miner (Cameraria ohridella), an alien pest in Europe that

15 lacks specialized enemies. We studied how the species richness and abundance of chalcids are

16 influenced by altitude, direction of an alien spread and host abundance of C. ohridella. We

17 quantified the numbers and species richness of chalcid wasps and the numbers of C. ohridella

18 that emerged from horse chestnut (Aesculus hippocastanum) leaf litter samples collected from 35

19 sites in the Czech Republic. Species richness of chalcids, which was considered an indicator of 
20 the possible adaptation of parasitoids to this alien host, was unrelated to C. ohridella abundance,

21 direction of spread, or altitude. Chalcid abundance, which was considered an indicator of

22 parasitism of the alien host, was strongly and positively related to C. ohridella abundance.

23 Chalcid abundance was negatively related to direction of spread and positively related, although

24 in a non-linear manner, to altitude. The relationship of chalcid abundance with direction of

25 spread and altitude was weaker than that with $C$. ohridella abundance. The results provide

26 evidence that biological control of the alien pest $C$. ohridella by natural enemies might develop

27 in the future.

\section{KEY WORDS}

30 Aesculus hippocastanum; altitude; chalcid wasps (Hymenoptera: Chalcidoidea); horse chestnut

31 leaf miner (Cameraria ohridella); leaf blotch miner moths (Lepidoptera: Gracillariidae); spread

32 direction

\section{Introduction}

The horse chestnut leaf miner, Cameraria ohridella Deschka and Dimic, 1986

36 (Lepidoptera: Gracillariidae), is causing ecological problems throughout Europe (Percival et al.

37 2011, Matosevic and Melika 2012). This species, which may have originated in the Balkans

38 (Valade et al. 2009), has increased its distribution (Sefrova and Lastuvka 2001) within a 
40 analysis of herbarium specimens indicates that the species was present in Europe at least as early

41 as 1879 (Lees et al. 2011).

In addition to causing aesthetic damage, mining by $C$. ohridella larvae may weaken or

43

44

45

46

47

48

49

50

even kill horse chestnut trees (Aesculus hippocastanum L.) - the mining is nearly constant

throughout the growing season because the insect has multiple, overlapping generations

(Matosevic and Melika 2012). The weakened trees increase the dustiness in urban environments and reduce the food supply for game in non-urban environments (Percival et al. 2011). This alien pest also harms native fauna (Pere et al. 2010) and other tree species in Europe (Freise et al. 2004).

Because $C$. ohridella overwinters as pupa in leaves that have fallen to the ground, $C$. ohridella numbers can be reduced by leaf removal (Gilbert et al. 2003, Kehrli and Bacher 2003). Leaf removal, however, is time consuming and thus expensive. In addition, the removed leaves must be properly composted to prevent leaf miner emergence in the following spring (Kehrli and Bacher 2004). Burning is not always possible because of weather or local regulations. $C$. ohridella may also be controlled by the use of insecticides or pheromones but these methods have been inconsistent in reducing the abundance of this pest and may harm native fauna (Wagner et al. 1996, Sefrova 2001). Although the application of synthetic inhibitors of chitin synthesis proved to be very effective (Blumel and Hausdorf 1997, Percival et al. 2012), the residues of these inhibitors may be highly stable (i.e., persistent) on horse chestnut leaves (Nejmanova et al. 2006). From a long-term perspective, breeding of horse chestnut tree with resistance to C. ohridella is an option (Mertelik et al. 2004). 

approximately 60 generalist parasitoids of C. ohridella (e.g. Grabenweger and Lethmayer 1999, Toth and Lukas 2005), Chalcid wasps (Hymenoptera: Chalcidoidea) are considered the most abundant and effective control agents (Grabenweger and Lethmayer 1999). The overall parasitism rate of non-native $C$. ohridella by indigenous enemies is affected by temporal factors (i.e. miner residence time) and spatial factors (i.e. geography) (Grabenweger et al. 2010). In addition, the attack of alien pests by native natural enemies is often delayed - as a consequence, the alien pest often suffers little biological control early in its invasion (Godfray 1994, Schonrogge and Crawley 2000).

Many geographical factors influence the spread, expansion and distribution of organisms, and especially important predictors are altitude (Lomolino et al. 2010) or direction of spread (Sefrova and Lastuvka 2001). These factors are often correlated with climate. Altitude, as an example, is known to well reflect geographical heterogeneity (Tognelli and Kelt 2004). At the spatial scale of the Czech Republic, south-to-north expansion of C. ohridella was correlated with latitude of $C$. ohridella (Sefrova and Lastuvka 2001). The relative importance of geography and host distribution on the distribution of parasitoids depends on the host-specificity of the

77 parasitoids, i.e., the effect of host distribution becomes more important as host-specificity increases (Sivinski et al. 2000, Skillen et al. 2000). Lethmayer 1999, Toth and Lukas 2005). Thus, we suspect that the number of species and individuals of non-specific parasitoids may be able to successfully respond to the high

82 abundance of this alien pest only if the parasitoids are limited by geography only marginally. 
84 and abundance of chalcid parasitoids influenced by geography and by the abundance of the alien

85 pest, C. ohridella?

86

\section{Material and Methods}

\section{$88 \quad$ Fig. 1.}

\section{Sampling sites}

91

During 2002, we studied the parasitism of the horse chestnut leaf miner by chalcid wasps

in 35 sites in the Czech Republic (Fig. 1), Each site contained a road lined with $\geq$ five horse chestnut trees that were infested with $C$. ohridella. These sites are typical of the patches with

94 horse chestnut trees in the Czech Republic and are known to be highly suitable for C. ohridella development (Sefrova and Lastuvka 2001).

\section{Study methods} of horse chestnut trees that were distant from other tree species to minimize the possibility that the litter was contaminated with leaves of other species. All samples were taken during the early

101 spring before the emergence of parasitoids (Grabenweger 2004). At each site, we collected $1 \mathrm{~m}^{2}$ $102(\approx 0.1 \mathrm{~m}$ height $)$ of pure horse chestnut leaf litter. 
All samples were covered with paper sheets and immediately transported to the

104

laboratory, where the litter was placed in emergence traps (cardboard boxes $0.6 \times 0.9 \times 0.2 \mathrm{~m}$ ) at $18-20^{\circ}$. All arthropods that emerged from the litter were trapped in $70 \%$ ethanol. The adult $C$. ohridella and chalcids were counted daily. The ethanol was replaced daily and the preserved chalcids were identified to species.

\section{Dependent variables and environmental predictors}

individuals of chalcid wasps that emerged from each litter sample. We used the list of Novakova and Nakladal (2008) for preliminary comparison of the parasitoid species and we found that all reared species are known to be associated with $C$. ohridella. It is indicated that species in their native areas are hosts of a higher number of species of parasitoids (Girardoz et al. 2006;

Grabenweger et al. 2010). Thus, the number of chalcid species was considered an indicator of possible adaptation of parasitoids to the alien host, i.e., an increase in species would suggest an increase in adaptation. On the other hand, the number of chalcid individuals was considered a possible indicator of chalcid abundance and rate of parasitism of the alien host (e.g. Arneberg et al. 1998).

\section{Table 1.}


124 richness and abundance of parasitoids that emerge from litter samples. The number of $C$.

125 ohridella adults that emerge (Host abundance) reflects $C$. ohridella abundance at each site.

126 Altitude of the site reflects geographical heterogeneity and correlates with climate. The direction

127 of spread (Spread direction) might well reflect the situation of species richness and abundance of

128 parasitoids during the time of active spread of invasive species. Thus, the direction of spread was

129 used as the third environmental predictor. As the spread of C. ohridella in the Czech Republic

130 had south-to-north direction (Sefrova and Lastuvka 2001; Sefrova 2003), degrees of latitude

131 were used.

132

133 Statistical analyses

All analyses were conducted in R 3.0.2. The potential bias caused by spatial

autocorrelation was controlled by Moran's correlograms using the spdep package (Bivand 2005).

136 Because our data did not show spatial bias at any distance (Moran's $I<-0.1 ; P>0.1$ ), we used

137 traditional statistical methods.

We then controlled for possible circular predicting and multicolinearity using the $\mathrm{HH}$ package (Heiberger 2009) and the value of variance inflation factor (VIF). This showed that $C$. ohridella abundance was not correlated with the other studied predictors (VIF; Table 1), i.e., 141 with altitude $(\mathrm{R}=-0.3 ; P=\mathrm{n} . \mathrm{s})$ or latitude $(\mathrm{R}=-0.3 ; P=\mathrm{n} . \mathrm{s}$.$) . Data for the number of species$ 142 and individuals of chalcids had Poisson distributions. 
145 dependent variables and the predictors were computed using generalized linear models and 146 generalized additive models with the gam package (Hastie 2011). Generalized additive models 147 were fitted by spline function.

\section{Results}

A total of 811 individuals $($ mean $=23.2 \pm 4.3 \mathrm{SE} ; \min =1 ; \max =118)$ of eight chalcid wasp species $(1.9 \pm 0.2 ; 1-4)$ emerged from the 35 litter samples, namely: Cirrospilus viticola $(0.1 \pm 0.1)$, Closterocerus trifasciatus $(0.8 \pm 0.4)$, Pediobius saulius $(2.1 \pm 1.4)$, Pnigalio agraules (11.5 \pm 2.9$)$, Pnigalio pectinicornis (0.7 \pm 0.3$)$, Pteromalus semotus (1.4 \pm 0.6$)$, Minotetrastichus frontalis (7.1 \pm 1.6$)$ and Sympiesis sericeicornis (1 individual). studied predictors (Table 3). The number of chalcid individuals that emerged (i.e. chalcid 157 abundance) was positively related to the number of $C$. ohridella that emerged from each sample, i.e. C. ohridella abundance explained nearly $50 \%$ of the variance in chalcid abundance. Chalcid abundance was negatively related with spread direction, and spread direction explained nearly $8 \%$ of the variance in chalcid abundance (Table 2 ). Unexpectedly, chalcid abundance was positively related with altitude (Table 2), although the response to altitude was not linear (Fig. 2; Table 3). Altitude explained less than $2 \%$ of the variance in chalcid abundance (Table 2).

Fig. 2. 
166

167

168

169

170

171

172

173

174

175

176

177

178

179

180

181

182

183

184

185

186

187

Table 3.

\section{Discussion}

Data in the current study were collected when the invasive horse chestnut leaf miner $(C$. ohridella) had become fully established in the Czech Republic (Sefrova and Lastuvka 2001). Since then, this invasive pest has expanded throughout central Europe and has established its first populations on the British Isles (Augustin 2013). Our results show that the abundance of parasitoids of $C$. ohridella was weakly related to predictors that are highly connected with geography, namely altitude and spread direction (linked to the latitude), but was relatively strongly related to $C$. ohridella abundance.

The number of parasitoid species was not significantly related to the studied predictors. This result indicates that the adaptation of indigenous parasitoid species to the alien pest was rather low, which is consistent with Girardoz et al. (2006) and it seemed that most of the parasitoid species were generalists, which agrees with Novakova and Nakladal (2008). On the other hand, parasitoid abundance was closely and positively related to C. ohridella abundance. In addition to being closely related to $C$. ohridella abundance, the abundance of generalist parasitoids seemed relatively high, even though the emergence of $C$. ohridella and its parasitoids are indicated to be poorly synchronized (Grabenweger 2004). Although parasitism rates as high as $50 \%$ have been reported for other leaf mining moths, the percentage of $C$.

ohridella attacked by parasitoids is often low and does not usually reach $20 \%$ (Grabenweger and Lethmayer 1999, Novakova and Nakladal 2008, Grabenweger et al. 2010). This low parasitism rate, which undoubtedly contributed to the heavy infestation of horse chestnut trees by $C$. 
188 ohridella in many places, probably results from former insufficient adaptation of the local

189 parasitoids to this recently introduced leaf miner. If such adaptation is possible, it will most

190 probably require more time (Zwolfer and Pschorn-Walcher 1968).

On the other hand, we suspect that generalist parasitoids may adapt to $C$. ohridella given

192

193

194

195

196

197

198

199

200

201

202

203

204

205

206

207

208

209

210

that their abundance increased with that of the pest although with delay. Grabenweger et al.

(2010) hypothesized that the adjustment of specialist parasitoids requires more than a few

decades. Recruitment and accumulation of native parasitoid species on introduced herbivores has

been documented (Cornell and Hawkins 1993), and exotic insects do not necessarily suffer lower enemy-induced mortality rates than natives (Hawkins et al. 1997). A quick shift of native

parasitoids to the new invasive host Tuta absoluta (Meyrick 1917) was observed in Italy

(Zappala et al. 2012). Similarly, another recent study indicated that resident generalist parasitoids and predators can work in conjunction to hinder the invasion of a herbivore (Hogg et al. 2013). It follows that although natural enemies have not prevented invasion of Europe by $C$. ohridella, based on our results we could suppose that successful biological control of invasive C. ohridella by natural enemies may develop in the future - because the total amount of chalcid individuals can better reflect the rate of parasitism of the alien host than number of adapted parasitic species.

The relationship to the spread direction fairly well illustrated that the number of parasitoids is decreasing with increasing distance from the area of origin. On the other hand, the increasing number of individuals of parasitoids was higher in higher altitudes, which is not common (Lomolino et al. 2010). This might correlate with relatively high altitude of the Lake Ohrid and surrounding areas in Macedonia and Albania, which is the area of origin of $C$.

ohridella (Valade et al. 2009). The result appears to indicate that aliens are more vulnerable to enemies in conditions that are close to their former area of distribution (e.g. Roy et al. 2011). 
212 Conclusions

The number of parasitoid species that emerged from leaf litter infested with the horse

214 chestnut leaf miner, C. ohridella, was not significantly related to C. ohridella abundance, altitude

215 or spread direction, a finding which possibly indicates a delayed response of indigenous enemies

216 to the expansion of their hosts. Although the abundance of generalist parasitoids was weakly

217 related to altitude and spread direction, it was strongly related to C. ohridella abundance. Our

218 results indicate a potential for biological control of C. ohridella by generalist parasitoids.

\section{Acknowledgments}

221

We dedicate this paper to the memory of Dr. Zdeněk Bouček, who helped us with the

222 determination of chalcid wasps. The authors thank Dr. Bruce Jaffee for linguistic improvements 223 and Petr Vopěnka for the map.

\section{References Cited}

226 Arneberg P., Skorping A., Grenfell B. and A.F. Read. 1998. Host densities as determinants of 227 abundance in parasite communities. Proceedings of the Royal Society of London B: Biological 228 Sciences 265: 1283-1289. 
229 Augustin, S. 2013. Distribution of Cameraria ohridella. The Natural History Museum.

230 (http://www.nhm.ac.uk/nature-online/species-of-the-day/biodiversity/alien-species/cameraria231 ohridella/index.html).

232 Bivand R. 2005. The Spdep Package. Comprehensive R Archive Network, Version 0.3-13.

233 Published online at http:// www.cran.r-project.org.

234 Blumel, S., and H. Hausdorf . 1997. Versuche zur Kontrolle von Cameraria ohridella Deschka 235 \& Dimić mit insektiziden Wachstumsregulatoren. Forstschutz Aktuell. 21: 16-18.

236 Cornell, H. V., and B. A. Hawkins. 1993. Accumulation of native parasitoid species on 237 introduced herbivores: a comparison of hosts as natives and hosts as invaders. Am. Nat. 141: $238 \quad 847-865$.

239 Freise, J. F., W. Heitland, and A. Sturm. 2004. Host-plant range of the horse-chestnut leaf miner, 240 Cameraria ohridella Deschka \& Dimic (Lepidoptera, Gracillariidae), a pest of the white 241 flowering horse-chestnut, Aesculus hippocastanum in Germany. Mitt. Dtsch. Ges. allg. angew. 242 Entomol. 14: 351-354.

243 Gilbert, M., A. Svaton, M. Lehmann, and S. Bacher. 2003. Spatial patterns and infestation 244 processes in the horse chestnut leafminer Cameraria ohridella: a tale of two cities. Entomol. 245 Exp. Appl. 107: 25-37.

246 Girardoz, S., M. Kenis, and D. Quicke. 2006. Recruitment of native parasitoids by an exotic

247 leafminer, Cameraria ohridella: host-parasitoid synchronization and influence of the 248 environment. Agricult. Forest Entomol. 8: 49-56. 
249 Godfray, H. C. J. 1994. Parasitoids: behavioral and evolutionary ecology. Princeton University

250 Press, Princeton, NJ.

251 Grabenweger, G. 2004. Poor control of the horse chestnut leafminer, Cameraria ohridella

252 (Lepidoptera: Gracillariidae), by native European parasitoids: a synchronisation problem. Eur. J.

253 Entomol. 101: 189-192.

254 Grabenweger, G., P. Kehrli, I. Zweimuller, S. Augustin, N. Avtzis, S. Bacher, J. Freise, S.

255 Girardoz, S. Guichard, W. Heitland, C. Lethmayer, M. Stolz, R. Tomov, L. Volter, and M.

256 Kenis. 2010. Temporal and spatial variations in the parasitoid complex of the horse chestnut

257 leafminer during its invasion of Europe. Biol. Invasions. 12: 2797-2813.

258 Grabenweger, G., and C. Lethmayer. 1999. Occurrence and phenology of parasitic Chalcidoidea 259 on the horse chestnut leafminer, Cameraria ohridella Deschka \& Dimic (Lep., Gracillariidae). J. 260 Appl. Entomol. 123: 257-260.

261 Hawkins, B. A., H. V. Cornell, and M. E. Hochberg. 1997. Predators, parasitoids, and pathogens

262 as mortality agents in phytophagous insect populations. Ecology. 78: 2145-2152.

263 Hastie T. 2011. GAM: Generalized Additive Models. R Package Version 1.04.1 Published online 264 at http:// www.cran.r-project.org.

265 Heiberger R.M. 2009. HH: Statistical Analysis and Data Display: Heiberger and Holland. R 266 package version 2.1-32. Published online at http:// www.cran.r-project.org.

267 Hogg, B. N., X. G. Wang, K. Levy, N. J. Mills, and K. M. Daane. 2013. Complementary effects 268 of resident natural enemies on the suppression of the introduced moth Epiphyas postvittana.

269 Biol. Control. 64: 125-131. 
270 Kehrli, P., and S. Bacher. 2003. Date of leaf litter removal to prevent emergence of Cameraria

271 ohridella in the following spring. Entomol. Exp. Appl. 107: 159-162.

272 Kehrli, P., and S. Bacher. 2004. How to safely compost Cameraria ohridella-infested horse

273 chestnut leaf litter on small compost heaps. J. Appl. Entomol. 128: 707-709.

274 Lees, D. C., H. W. Lack, R. Rougerie, A. Hernandez-Lopez, T. Raus, N. Avtzis, S. Augustin, 275 and C. Lopez-Vaamonde. 2011. Tracking origins of invasive herbivores using herbaria and 276 archival DNA: the case of the horse-chestnut leafminer. Front. Ecol. Environ. 9: 322-328.

277 Lomolino, M. V., B. R. Riddle, R. J. Whittaker, and J. H. Brown. 2010. Biogeography, Fourth 278 edition. Sinauer, USA.

279 Matosevic, D., and G. Melika, G. 2012. Diversity of parasitoid assemblages of native and alien 280 leaf miners in Croatia. Sumar. List. 136: 367-376.

281 Mertelik, J., K. Kloudova, and P. Vanc. 2004. Occurrence of Aesculus hippocastanum with high 282 degree of resistance to Cameraria ohridella in the Czech Republic. Acta Fytot. Zoot. 7: 204283205.

284 Nejmanova, J., J. Cvacka, I. Hrdy, J. Kuldova, J. Mertelik, A. Muck, Jr., P. Nesnerova, and A. 285 Svatos. 2006. Residues of diflubenzuron on horse chestnut (Aesculus hippocastanum) leaves and 286 their efficacy against the horse chestnut leafminer, Cameraria ohridella. Pest Manag. Sci. 62: $287 \quad 274-278$.

288 Novakova, P., and O. Nakladal. 2008. Pripadova studie parazitoidu klinenky jirovcove 289 (Cameraria ohridella Deschka et Dimic, 1986) v Ceske republice v letech 2001-2005. Zpr. Les. 290 Vyzk. 53: 12-21. 
291 Percival, G. C., I. Barrow, K. Noviss, I. Keary, I., and P. Pennington. 2011. The impact of horse

292 chestnut leaf miner (Cameraria ohridella Deschka and Dimic; HCLM) on vitality, growth and 293 reproduction of Aesculus hippocastanum L. Urban For. Urban Greening. 10: 11-17.

294 Percival, G. C., J. Banks, and I. Keary. 2012. Evaluation of organic, synthetic and physical 295 insecticides for the control of horse chestnut leaf miner (Cameraria ohridella). Urban For. Urban 296 Greening. 11: 426-431.

297 Pere, C., S. Augustin, R. Tomov, L. H. Peng, T. C. Turlings, and M. Kenis. 2010. Species 298 richness and abundance of native leaf miners are affected by the presence of the invasive horse299 chestnut leaf miner. Biol. Invasions. 12: 1011-1021.

300 Roy H.E., Handley L.J.L., Schonrogge K., Poland R.L. and B.V. Purse. 2011. Can the enemy 301 release hypothesis explain the success of invasive alien predators and parasitoids? Biocontrol 56: $302 \quad 451-468$.

303 Schonrogge, K., and M. J. Crawley. 2000. Quantitative webs as a means of assessing the impact 304 of alien insects. J. Anim. Ecol. 69: 841-868.

305 Sefrova, H. 2001. Control possibility and additional information on the horse-chestnut leafminer 306 Cameraria ohridella Deshka \& Dimic (Lepidoptera, Gracillariidae). Acta Univ. Agricult. 307 Silvicult. Mend. Brun. 49: 121-127.

308 Sefrova H. 2003. Invasions of Lithocolletinae species in Europe-causes, kinds, limits and 309 ecological impact (Lepidoptera, Gracillariidae). Ekologia 22: 132-142. 
310 Sefrova, H., and Z. Lastuvka. 2001. Dispersal of the horsechestnut leafminer, Cameraria

311 ohridella Deschka \& Dimic, 1986, in Europe: its course, ways and causes (Lepidoptera:

312 Gracillariidae). Entomol. Zeit. 111: 194-198.

313 Sivinski, J., J. Pinero, and M. Aluja. 2000. The distributions of parasitoids (Hymenoptera) of

314 Anastrepha fruit flies (Diptera: Tephritidae) along an altitudinal gradient in Veracruz,

315 Mexico. Biol. Control. 18: 258-269.

316 Skillen, E. L., J. Pickering, and M. J. Sharkey. 2000. Species richness of the Campopleginae and

317 Ichneumoninae (Hymenoptera: Ichneumonidae) along a latitudinal gradient in eastern North

318 American old-growth forests. Environ. Entomol. 29: 460-466.

319 Tognelli, M. F., and D. A Kelt. 2004. Analysis of determinants of mammalian species richness in

320 South America using spatial autoregressive models. Ecography. 27: 427-436.

321 Toth, P., and J. Lukas. 2005. Parasitic Ichneumonoidea on the horse chestnut leaf miner,

322 Cameraria ohridella (Lepidoptera: Gracillariidae) in Slovakia. J. Pest Sci. 78: 151-154.

323 Valade, R., M. Kenis, A. Hernandez-Lopez, S. Augustin, N. Mari Mena, E. Magnoux, R.

324 Rougerie, F. Lakatos, A. Roques, and C. Lopez-Vaamonde. 2009. Mitochondrial and

325 microsatellite DNA markers reveal a Balkanic origin for the highly invasive Horse-Chestnut leaf

326 miner Cameraria ohridella (Lepidoptera, Gracillariidae). Mol. Ecol. 18: 3458-3470.

327 Wagner, D. L., J. Peacock, J. L. Carter, and S. E. Talley. 1996. Field assessment of Bacillus

328 thuringiensis on nontarget Lepidoptera. Environ. Entomol. 25: 1444-1454.

329 Walsh C. and R.Mac Nally. 2011. Package 'hier.part'. Published online at http:// www.cran.r330 project.org. 
331 Zappala, L., U. Bernardo, A. Biondi, A. Cocco, S. Deliperi, G. Delrio, M. Giorgini, P. Pedata, C.

332 Rapisarda, G. T. Garzia, and G. Siscaro. 2012. Recruitment of native parasitoids by the exotic

333 pest Tuta absoluta in Southern Italy. Bull. Insectology. 65: 51-61.

334 Zwölfer H. and H.Pschorn-Walcher .1968. Wie verhalten sich Insektenparasiten gegenüber

335 eingeschleppten, faunenfremden Wirten?.Anzeiger für Schädlingskunde 41: 51-55. 